The BDJ News section accepts items that include general news, latest research and diary events that interest our readers. Press releases or articles may be edited, and should include a colour photograph if possible. Please direct your correspondence to the News Editor, Arveen Bajaj at the BDJ, The Macmillan Building, 4 Crinan Street, London N19XW or by email to bdj@bda.org

\section{Showcasing excellence}

Practice teams are being given the opportunity to showcase their achievements at the Denplan National Conference in September. Delegates have been invited to submit case studies on how they have improved the quality of their practice via their treatments or the service offered to patients, in line with the Conference's theme, 'Marketing Quality Care'.

The aim is to encourage best practice to be shared throughout the profession and to motivate other practice teams. 'Many of our member practices have shown tremendous commitment towards developing their practices for the benefit of their patients, and other practice teams can usefully learn from their experiences' said Dr Roger Matthews, Denplan's chief dental officer.

The case studies will be published at the Conference, which takes place at the Marriott Forest of Arden Hotel and Country Club from 22-24 September 2006. Practices wishing to submit a case study can order a copy of the National Conference brochure, which contains submission guidelines, by phoning 08001695697.

\section{Success for Stubley Lane}

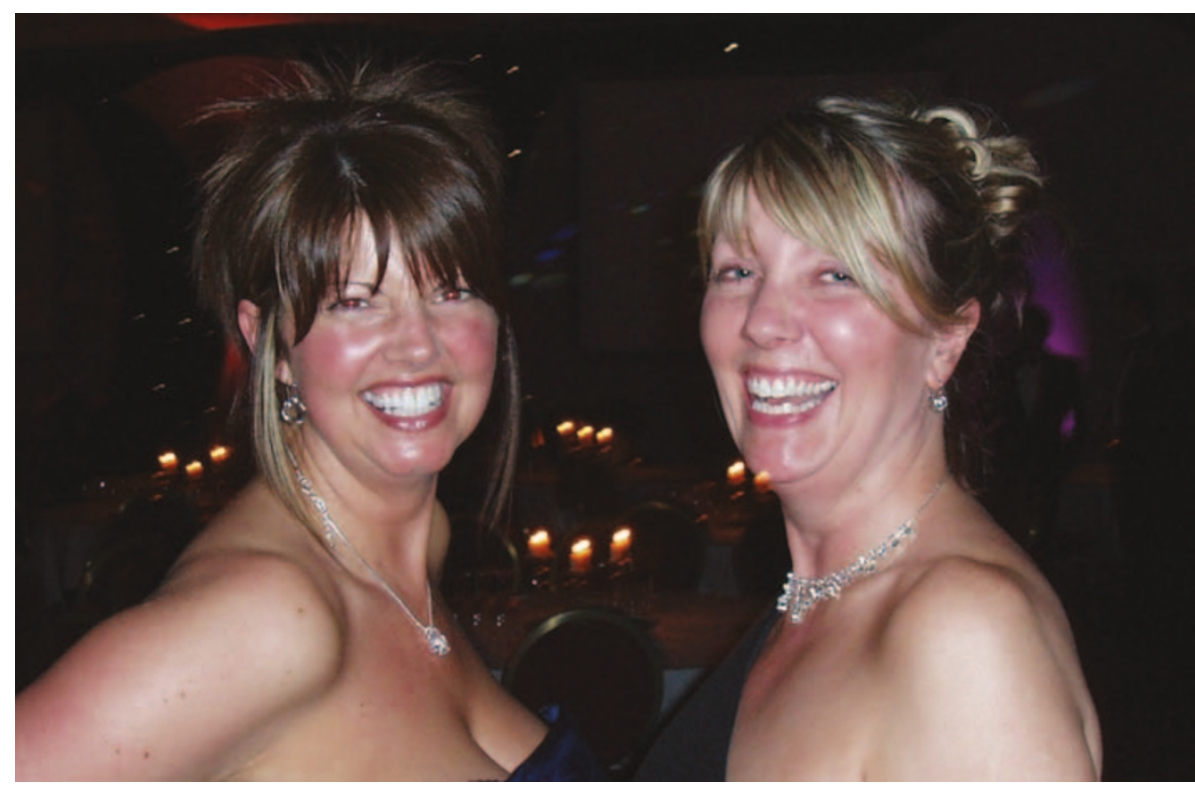

Two staff members from Stubley Lane Dental Centre were recognised at this year's National Dental Awards. Karen Bell was awarded Dental Nurse of the Year 2006, while Kate Carr received a Highly Commended in the Manager of the Year 2006 category. Finalists for the Awards are chosen from testimonials from patients and nominations from work colleagues. Stubley Lane did particularly well this year, having two other nominations in the categories Dentist of the Year and Therapist of the Year for David Ward and Alison Horton. Winners Karen and Kate are pictured here at the awards ceremony.

\title{
Cooking method can affect erosion
}

Researchers at the University of Dundee have discovered that different methods of cooking vegetables can vary their effects on dental erosion. A new study led by Dr Graham Chadwick from the School of Dentistry, found that oven-roasted ratatouille was significantly more acidic than the traditional stewed version of the dish (Chadwick R G. Eur J Prosthodont Restor Dent 2006; 14: 28-31).

The research was based on reports that a vegetarian diet may give more risk of dental erosion due to the acidic nature of a large number foods involved, including fruit and vegetables. Ratatouille is a popular vegetarian dish made from tomatoes, onions, aubergines, courgettes and red and green peppers, and can be either stewed on a stove-top or oven roasted. The team looked to see

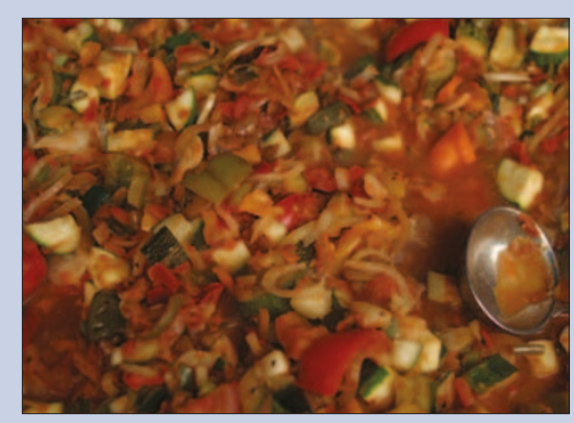
whether the cooking method had any effect on its final acidity and therefore its potential for contributing to dental erosion.

Although ratatouille is always acidic, oven roasting was found to increase the acidity of the dish to the point where it was equivalent to some carbonated drinks. 'The finding that cooking method has an impact on the acidity of food is an interesting and useful tool for dentists when advising patients on ways to reduce their chances of dental erosion; said Dr Chadwick.

The Dundee team also looked at whether the cooking method had an impact on individual vegetables and fruits. They found that there was no effect on the acidity of tomatoes or onions, but roasting resulted in more acidic aubergines, green peppers and courgettes. Red peppers were found to be more acidic when stewed. 


\section{DIARY}

June

10th European Congress Dentomaxillofacial Radiology

Venue: Provinciehuis, Leuven, Belgium

Date: 31 May-2 June 2006

www.10ecdmfr.be

112th Meeting of the American Dental

Society of Europe

Venue: Dubrovnik, Croatia

Date: 27-30 June 2006

Tel: 01413310088

www.adse.co.uk

84th General Session \& Exhibition of the International Association for Dental

Research

Venue: Brisbane, Australia

Date: 28 June-1 July 2006

www.dentalresearch.org/meetings/brisba ne/index.html

July

82nd Congress of the European Orthodontic Society

Venue: Hofburg Congress Center, Vienna, Austria

Date: 4-8 July 2006

Tel: (+43/1) 53116 - 38

Fax: (+43/1) $53116-61$

Email: azmedinfo@media.co.at

September

The British Society of Paediatric Dentistry Annual Scientific Conference

'The Art \& the Science'

Venue: The Hilton, Leeds City

Date: 12-15 September 2006

www.bspd.co.uk/conf-2006.html

European Society for Oral Laser Applications/Hellenic Society for Oral Laser Applications 1st Mediterranean Laser Congress

Venue: Hilton Hotel Rhodes Resort, Greece

Date: 21-23 September 2006

Email: esola2006@medacad.org www.esola.at

FDI Annual World Dental Congress

Venue: Shenzhen, China

Date: 22-25 September 2006

Email: congress@fdiworldental.org www.fdiworldental.org

\section{Minty Mouth Challenge goes for the record!}

Aquafresh have announced a new event involving 50,000 children, 1.6 million teeth and a world record! The Aquafresh Minty Mouth Challenge aims to break the current Guinness World Record for the largest simultaneous toothbrushing session and will take place on 18 June as part of the BT Giant Sleepover, an annual fundraising event for children and families to raise money for ChildLine.

The Aquafresh Minty Mouth Challenge will take place on the Sunday morning of the event, when all children and their parents will be co-ordinated at venues across the UK to brush their teeth simultaneously for two minutes. 'This is a new challenge for the morning of the sleepover and is designed to encourage children to learn good oral health care habits and have fun at the same time, said Harriet Whiting, Senior Brand Manager of Aquafresh. The company will also provide materials to give children top tips on looking after their teeth, including information on brushing technique, amount of toothpaste required and the importance of brushing for two minutes.

The current simultaneous toothbrushing record for multiple venues stands at 31,424 and was set in 2003. Organisers hope that the BT Giant Sleepover will attract more than the 31,584 children who took part in the record event in 2005 and set a new world record for both toothbrushing and sleepovers. More information can be found at www.giantsleepover.com.

\section{New health website launched}

The British Medical Journal officially launched their new health website for the public, BestTreatments.co.uk, on 9 May. The site is a patient's version of Clinical Evidence, the resource that doctors use for information and the latest evidencebased research, and is currently the only independent, evidence-based information resource available to patients.

The information on BestTreatments.co.uk is easy to read and jargon-free and the site aims to state clearly which treatments do and don't work, and which require more research, for any given condition. 'Crucially BestTreatments.co.uk is impartial - not sponsored by drug companies for instance - so patients know they are getting impartial advice on which treatments work and which don't; said Cherill Hicks, BestTreatments.co.uk UK Editor. The site also tackles questions such as whether over the counter hayfever remedies are worth the money, and whether it is worth a child having an operation for grommets to cure ear infections.

The hope is that the site will help GPs and their patients to share decision making

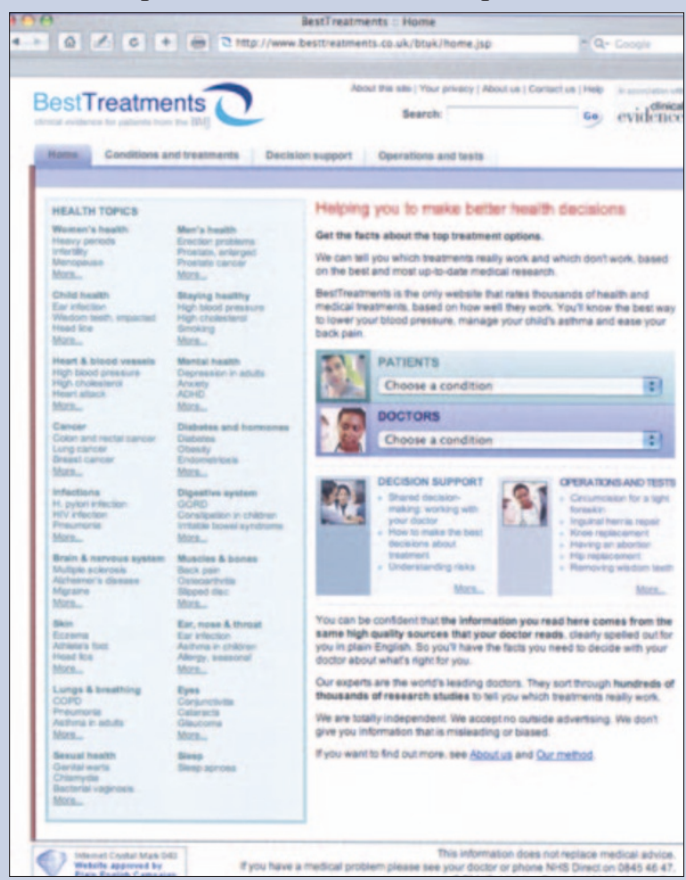
about care. Dr Brian Fisher, a GP from Lewisham, London, said that patients want more information about their conditions and treatments, but do not usually receive enough. 'Patients want to be involved in decision making around their care,' he said. 'When patients are offered information, outcomes are often better and they may use the NHS less.'

The website will be updated with the latest information around once a month, with every condition updated at least once a year. Conditions such as impacted wisdom teeth and burning mouth syndrome are already covered on the site and more oral health information may be included as the site develops. For more information, visit the site at www.besttreatments.co.uk. 


\section{Periodontitis in pregnancy may increase CRP}

Pregnant women with periodontitis have on average 65\% higher C-reactive protein (CRP) levels in their blood than those who are healthy, according to a recent study in the Journal of Periodontology. ${ }^{1}$ The findings may help explain the association between periodontitis and adverse pregnancy outcomes.

High CRP levels are a marker of systemic inflammation and have also been associated with adverse pregnancy outcomes, including pre-eclampsia and premature delivery. Previous research into the relationship between CRP and periodontitis has found that CRP levels often decrease after standard periodontal therapy. The new results show that elevated CRP may indeed by caused by periodontal inflammation and infection, according to author Dr Waranuch Pitiphat, from Khon Kaen University in Thailand. 'If this is the case, CRP could amplify the inflammatory response and ultimately cause adverse pregnancy outcomes.' she said.

This is the first study that has looked at periodontitis and CRP levels in pregnant women, as evidence for an association between the two has so far come from research looking at adults who were not pregnant. 'This is one more study that really drives home the importance of taking care of the entire body including oral health,' said Kenneth A. Krebs, President of the American Academy of Periodontology.

Dr Pitiphat stressed that the links between periodontitis and adverse outcomes in pregnancy required more investigation. 'Alternatively, periodontal disease and CRP may share a common risk factor for predisposing individuals to a hyperinflammatory response, she continued. 'More research is clearly needed to further our understanding about the association between periodontal disease and adverse pregnancy outcomes.'

1. Pitiphat $W$, Joshipura $K J$, Rich-Edwards J W et al. Periodontitis and plasma C-reactive protein during pregnancy. J Periodonto/ 2006; 77: 821-825.

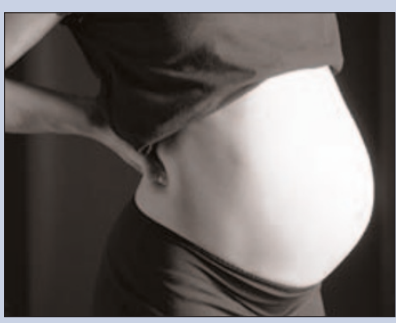

\section{Official Showcase website goes live}

The official website for this year's London Dental Showcase is now live at www.dentalshowcase.com. Designed in line with the 'Art of Dentistry' theme adopted for this year,

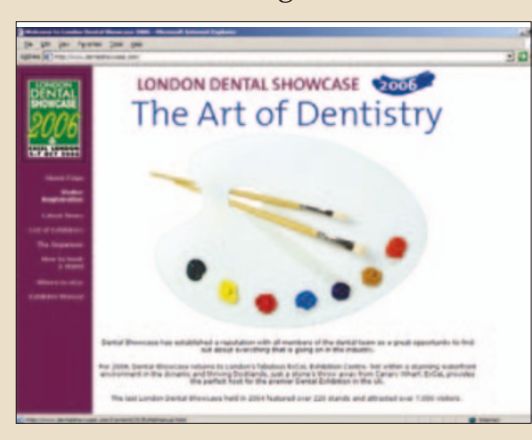
visitors can use the site to reserve complimentary tickets to the event, as well as being able to view up-to-date exhibitor lists and floorplans and read the latest news and developments surrounding the event. As well as being available online, complimentary tickets can also be reserved by telephoning the registration hotline on 01494 789959. Advance registration closes on 30 September 2006 and this year's Showcase takes place from 5-7 October at ExCeL, London.

\section{Benevolent Fund prize winner}

Mr W D Cummins of Norfolk was the lucky winner of first prize in the BDA Benevolent Fund's 2005 Christmas draw. Mr Cummins, pictured, was presented with a cheque for $£ 6,000$ by organiser Mavis Phipps, a community dentist from Kent.

The Benevolent Fund assists dentists and their families in times of need, helping to resolve both short term difficulties and longer term problems. The Fund responds to appeals from dentists who are suffering anything from financial hardship to drug addiction and from old age to marriage breakdown. It is heavily dependent on donations and fundraising events to finance its charitable activities. The 2005 draw raised $£ 40,000$ and the Fund would like to extend its sincere thanks to all who made donations throughout 2005.

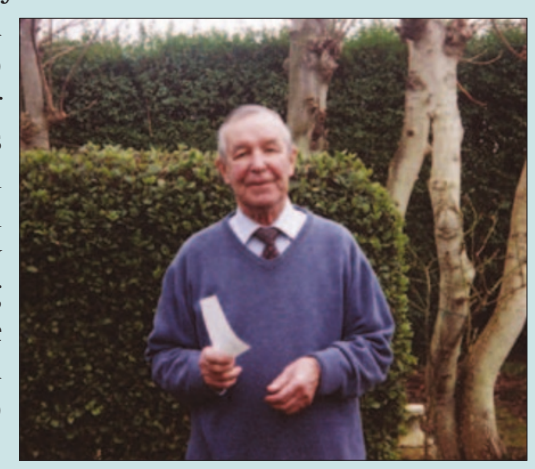




\section{Clinical trial requests patients}

Referrals are invited of suitable children who have avulsed and had replanted a permanent tooth or teeth, to take part in a clinical trial looking at the success of two follow-up protocols. Children can be accepted onto the trial where the initial replantation and splinting has been carried out by a general dental practitioner, community dentist or within a hospital setting (ACtE or maxillofacial surgery).

The study is a multi-centred randomised controlled trial involving five centres (Leeds, Glasgow, Belfast, Newcastle and Eastman, London). Practitioners are asked to please refer the child to the nearest centre as soon as possible after the emergency replantation and splinting, as to be included in the trial they must be seen within ten days. Each patient requires five visits to the participating dental hospital over a period of one year where all follow up treatment for the avulsed tooth will be provided. As this is a paediatric study only children under the age of 16 will be admitted. Those children referred but unwilling or not fulfilling the inclusion criteria will not prejudice the care they receive.

For more details of the inclusion criteria or any other information, please contact Peter Day on 07963054090 or by email at p.f.day@leeds.ac.uk. Alternatively please contact the Principle Investigator at each centre:

- Eastman (London) - Dr Paul Ashley

- Glasgow Dental School - Prof Richard Welbury

- Leeds Dental Institute - Dr Peter Day \& Prof Monty Duggal

- Newcastle Dental School - Dr Ben Cole

- Royal Belfast Hospital for Sick Children and School of Clinical Dentistry - Dr Terry Gregg.

\section{Clinical governance success}

Clinical governance sessions run by Bradford South \& West PCT proved extremely popular with dental teams in the area.

Risk assessment, clinical audit and child protection sessions run by PCT experts featured strongly and the importance of clinical governance for the whole practice team was clearly explained by Lesley Cave, the PCT's Acting Director of Clinical Governance. 'All the presentations evaluated well and a number of possibilities for supporting practices further with clinical governance have been identified, said Roger Furniss, the PCT's Dental Practice Adviser. 'Practices have been very much encouraged and assisted in the use the BDA Clinical Governance Kit, which was purchased for those practices who expressed an interest but hadn't already obtained it.'

Premises risk assessments and clinical audits on aspects of radiology and periodontology were carried out by practices and reported at the event. These sessions raised a number of important points that proved beneficial to all those present. Pictured is dental practitioner Mark Speight giving a report of his practice clinical audit.

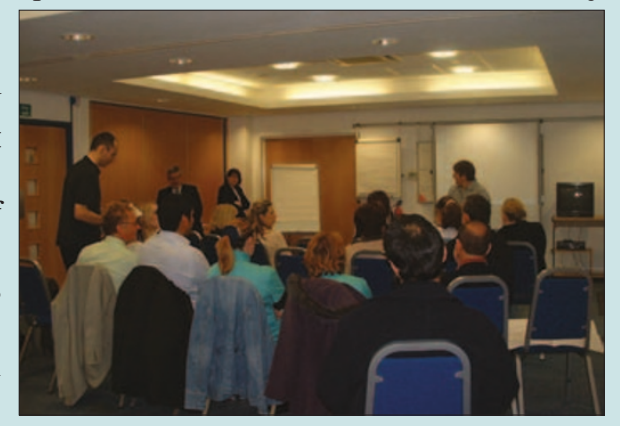

\section{The art and the science}

This year's British Society of Paediatric Dentistry conference will focus on the fusion of the two contrasting concepts art and science. The event, to be held in Leeds from 12-15 September, will feature a host of nationally and internationally renowned speakers coming together to give an insight into the diversity of management regimes available for conditions of interest to anyone providing oral health care for children.

Keynote presentations will cover topics including amelogenesis imperfecta and epidermolysis bullosa, with other sessions covering erosion, care of the periodontal ligament and advances in pulp biology. As usual there will also be a programme of social events and the opportunity to compete for one of three prestigious prizes - the Young Researcher's Prize, the Poster Prize and the Clinical Case Presentation Prize.

For further information please visit www.bspd.co.uk/conf-2006.html.

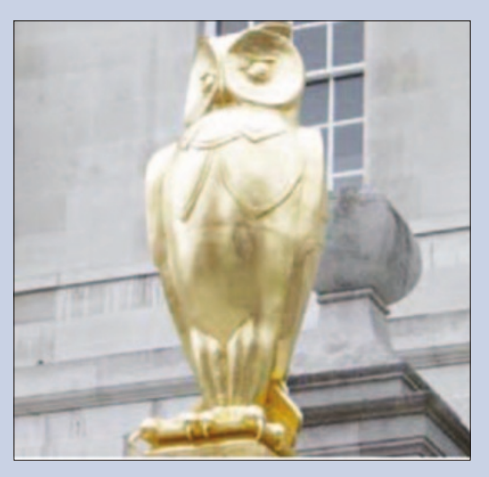

